\title{
The cloud computing systems' adoption in the higher education sector in Oman in light of the COVID-19 pandemic
}

\author{
Salim Al-Hajri' ${ }^{1}$, Abdelghani Echchabi², Abdullah Mohammed Ayedh ${ }^{3}$, Mohammed Mispah Said \\ Omar $^{4}$ \\ ${ }^{1,4}$ A’Sharqiyah University, Al-Yahmadi, Ibra, Oman \\ ${ }^{2}$ Higher Colleges of Technology, Dubai Academic City, United Arab Emirates \\ ${ }^{3}$ Islamic Science University of Malaysia, Negeri Sembilan, Malaysia
}

\section{Article Info \\ Article history: \\ Received Feb 1, 2021 \\ Revised Jun 23, 2021 \\ Accepted Jul 19, 2021 \\ Keywords: \\ Cloud computing \\ COVID-19 \\ E-learning \\ Higher education}

\begin{abstract}
The objective of the research was to find out the key factors that influence the acceptance and usage of cloud computing systems in the Omani higher education sector, with special emphasis on the COVID-19 outbreak. For this purpose, a quantitative research approach was conducted where 200 students from several Omani higher education institutions were surveyed, and by using Partial Least Square (PLS) to analysis the collected data. The findings revealed that the intention to use cloud computing in this context is significantly dependent on its perceived ease of use, usefulness, perceived reliability and responsiveness. It is noteworthy that this is one of the early studies that address the subject of cloud computing usage during times of crises, and specifically the COVID-19 outbreak. As such, it provides significant contributions in the area of technology adoption.
\end{abstract}

This is an open access article under the CC BY-SA license.

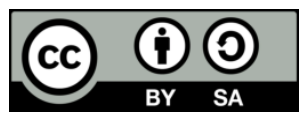

\section{Corresponding Author:}

Abdelghani Echchabi

Higher Colleges of Technology

Dubai Academic City

United Arab Emirates

Email: Abdelghani.mo@gmail.com

\section{INTRODUCTION}

In early 2020, the world has witnessed almost a total shutdown of all aspects of life regardless of developed, developing or under developed countries due to Coronavirus (COVID-19) pandemic. In the education sector, the COVID-19 disruption is far-reaching. Due to the pandemic of COVID-19 on the education sector could be classified into two phases, namely, the total closure phase of all learnings activities, then the phase of transforming from traditional physical face to face to the e-learning and online platforms [1]. According to UNICEF report on April 2020, on COVID-19 and its implications on children, the schools in over 188 countries have been closed and that obstructed $90 \%$ of the school students worldwide from accessing education services [2].

The higher education in Sultanate of Oman is severely disrupted as well. The Omani Supreme Committee on COVID-19 has decided to suspend schools and educational institutions' classes. On the other hand, the higher education institutions decided to apply online education during this emergency situation. It is noteworthy that the Omani higher education system has been undergoing substantial reforms and developments for the past few decades. This period witnessed a significant increase in high school graduates and the government had successfully managed to accommodate them into the higher education institutions at various levels [3], and the government is well determined to maintain this trend even during the COVID-19 outbreak. 
Although, the blended learning approach in higher education institutions in Oman was applied combining traditional classroom learning and online educational methods, that is still not adequate for periods of crises [4], which includes the case of COVID-19 pandemic. He argued that Cloud computing system is the right means to implement to advance and reform the educational activities to virtual online platform in similar circumstances.

With regards the education sector, the e-learning or cloud computing system practice could be either synchronous or asynchronous [3]. Synchronous e-learning is a live online class, where there is an interaction between the participants via the internet platform (e.g., Microsoft Team, Google Class, Zoom, Skype, YouTube live, and Facebook live). Whereas, asynchronous e-learning is the process where education content, instructions, and learning are recorded in forms and shared as resources with students who can access them anytime and anywhere. These resources could be in form of documents, videos, and voice records.

There are several challenges facing adoption and usage of Cloud computing system, such as the information technology (IT) infrastructure, internet connection quality, and the user's willingness and ability (e.g., lecturers, students, administration, IT support) [3], [5]-[7]. Accordingly, the current research focuses on the students' acceptance of Cloud computing systems.

Although, the higher education sector has been flourishing, there is still a serious lack of literature in the Arab regain in general and in the Gulf countries specifically with regards the Cloud computing in higher education [3]-[6], especially in periods of crises such as the COVID-19 outbreak. It is argued that this current study is the first to explore the acceptance of cloud computing systems amongst the Omani university students during the COVID-19.

\section{LITERATURE REVIEW}

The adoption and usage of cloud computing with all its facets has received a significant attention in the literature in the recent years. In this regard, multiple theoretical and empirical studies were carried in different settings and fields. For instance, Chen, Chen, and Chang [8] examined the factors that cause the adoption and usage of cloud computing system in Taiwan. The study used a combination of the Technology Acceptance model (TAM), Diffusions Innovation Theory (DIT), and the Theory of Planned Behavior (TPB). The study included a total sample of 1,069 individuals from different sectors and different backgrounds and used Structural Equation Modelling (SEM) approach for data analysis. Their findings showed that perceived ease of use, compatibility, perceived usefulness, and attitude have a significant positive influence on behavioral intention.

In another context, Al-Sharafi, Arshah, an Abu-Shanab [9] attempted to identify the vital reasons that influence the usage of services of cloud computing in organizations, through conducting a comprehensive literature review. The study concluded that the relative advantage, complexity, perceived security and privacy, compatibility, top manager's support, cost reduction, competitive pressure, IT readiness, size of the organization, vendor support, regulations and government policy, trialability, perceived reliability, perceived availability, uncertainty and perceived trust are the significant factors driving the permanent use of cloud computing tools in international institutions.

On the other hand, Kandil, et al. [10] investigated the variables impacting the cloud computing practices in Egypt. The authors covered a sample of 432 organizations from different sectors, and used SEM for data analysis. Their results indicated that relative advantage, compatibility, complexity, security, top management support, technology eagerness, internet services provider, maturity and performance, telecommunication infrastructure, trading partner support, and trading partner pressure have a substantial influence on the adoption of cloud computing.

Moreover, Stieninger, et al. [11] explored the factors affecting cloud computing systems (cloud storage, cloud mail and cloud office). The sample consisted of 203 individuals from different regions globally. Data analysis was performed applying variance-based structural equation modelling (VSEM), and the findings revealed that compatibility, relative advantage, security, trust, and complexity have a significant influence on the attitude towards cloud computing adoption, but not on its actual usage.

In addition, Tripathi [12] investigated the determinants of cloud computing acceptance and usage in India. The sample of 458 respondents from adopting and non-adopting firms was used. Using SEM for data analysis, the results revealed that the factors related to perceived benefits have significant impact on the cloud computing adopter organizations than negative factors. On the other hand, the effect of the negative factors such as perceived risk and perceived high cost were found to be relatively more impactful in the case of non-adopting companies.

In specific case of SMEs, Hassan, et al. [13] explored the factors that affect the Malaysian SMEs' adoption of cloud computing. The study covered a sample of 132 senior managers of Malaysian SMEs. Using the PLS method, the findings revealed that external pressure and IT resources have a significantly influence 
on cloud computing adoption. Similarly, Senarathna, et al. [14] examined the priority factors that influence Australian SMEs' adoption of cloud computing system. The study covered a sample of 149 Australian SMEs. Using multiple regression method to analysis the collected data. The results showed that SMEs were affected by factors related to advantaging their organizational capability (i.e., relative advantage, quality of service and awareness) rather than risk-related factors (i.e., security, privacy and flexibility).

In the case of government sectors, Al-Rawahna, Hung, and Chen [15] examined the level of preparedness of the Jordanian government sectors to implement cloud-computing, by surveying 132 government officials in different positions. Using the PLS approach, the authors found that higher management support, organizational capability, government policies and organizational readiness have a significant role in the adoption of cloud computing by the government sector in Jordan.

In the Indonesian local government scenario, Salam and Ali [16] attempted to unravel the factors that impact the employees' adoption of cloud computing, by applying the Unified Theory of Acceptance and Use of Technology (UTAUT) theory. The study covered 123 respondents and applied SEM for data analysis. The findings indicated that performance expectations, business expectations, and perception of availability had a positive effect on the local government employees' intention to use cloud computing.

In the health sector, Sadoughi, Ali, and Erfannia [17] investigated and compared the factors that affect the adoption of cloud computing in health and non-health sectors. From a review of 541 articles, the authors found that the factors that mostly affect cloud computing implementation are pigeon-holed as the factors were related to technological, organizational, environmental, and individual aspects. Under the technological factors, the relative advantage, complexity, compatibility, technical readiness, security, and reliability. The organizational factors include top management support, firm size, provider support, vendor credibility, employee knowledge, and business strategy. The environmental factors include pressure from comparative, trading partner pressure, legal issues, market regulations and policies, government support, and political orientation. Finally, the individual factors include perceived benefit, perceived usefulness, perceived ease of use, end user satisfaction, and end user involvement.

Similarly, Nassoura [18] explored the cloud computing adoption in the Jordanian healthcare sector and the factors that influence it. The study covered a total of 250 respondents and used linear regression for data analysis. The findings showed that security, privacy, complexity, compatibility, top management support, technology readiness, facilitating conditions, and environmental uncertainty have a significant effect on the adoption of cloud computing systems in the healthcare sector in Jordan. In the specific higher education sector, Chaveesuk, Wutthirong, and Chaiyasoonthorn [19] attempted to develop a conceptual framework for the behavioral intention towards cloud computing usage in the higher education organizations in Thailand. The authors used a combination of the technology acceptance model (TAM) and the Service and System Quality (SSQ) model. The final model includes three major dimensions, namely, perceived usefulness, perceived ease of use and service and system quality.

Furthermore, Asadi, Abdekhoda, and Nadrian [20] examined the variables that would influence the teachers' intention to use cloud computing as infrastructure for Smart Education. The study covered a total sample of 240 faculties from Iranian universities, and the data were analyzed using regression analysis following the structural equation modeling technique. The findings revealed that Attitude, perceived behavior control and privacy have a significant direct effect on academicians' intention to adopt cloud computing.

Similarly, Ahmed, Hoda, and Alahmari [21] attempted to identify the critical factors for cloud computing adoption success in the education sector following the interpretive structural modelling (ISM) technique. The developed model consisted of dimensions from cloud computing, organizational, technological and mobile learning domains. Particularly, relative advantage was found to be the most important factor in adopting cloud computing by learners.

It is worth noting that cloud computing acceptance and implementation have not been examined in the context of crises like the medical crisis of COVID-19. This can be explained by the fact that COVID-19 did not have any similar precedent in terms of magnitude, repercussions, and persistence that was accompanied by significant advances in educational technology and its usage.

Nevertheless, Ramluckan and Niekerk [22] emphasized the significant benefits of cloud computing systems in the crises era, as an efficient and convenient tool for crisis response, considering the different security measures and requirements for different types of crises. Overall, it can be deduced that rigorous empirical research on cloud computing usage and adoption are still relatively scarce, and even scarcer in the case of GCC countries (Oman, Bahrain, Kuwait, Saudi Arabia, UAE, and Qatar) and similar settings, especially in period of crises like the COVID-19 outbreak. Hence, findings of this study can also be extended to similar settings. The above studies have developed and tested different models including different dimensions and factors for different sectors and fields. In line with these studies, the most significant factors were incorporated in the current study based on an extension of the technology acceptance model [23]. Accordingly, the model incorporates four factors, namely, perceived ease of use, perceived usefulness, 
reliability and responsiveness. Accordingly, the following hypotheses were posited, and have been tested using PLS method: Perceived ease of use has a positive influence on the intention to use cloud computing systems in higher education in Oman during COVID-19 (H1); Perceived usefulness has a positive influence on the intention to use cloud computing systems in higher education in Oman during COVID-19 (H2); Reliability has a positive influence on the intention to use cloud computing systems in higher education in Oman during COVID-19 (H3); and Responsiveness has a positive influence on the intention to use cloud computing systems in higher education in Oman during COVID-19 (H4).

\section{RESEARCH METHOD}

This study aimed to inspect the cloud computing systems acceptance in the higher education sector considering COVID-19 outbreak. Specifically, the study attempts to identify the main factors and reasons which might have potential impact on the acceptance of cloud computing systems in the higher education industry in Oman, especially at the surge of COVID-19 pandemic. It covers a sample of 200 respondents from the major universities in the various regions in Oman, and applies Partial Least Square (PLS) approach to analyse the data, which has a higher ability to robustly incorporate more independent variables, and provides more predictive accuracy of the regression model compared to other methods. Out of the distributed questionnaires, 183 were returned. The achieved response rate was $92 \%$.

The questionnaire was developed to gather information Omani students' perception towards the attributes of cloud computing systems as well as their intention to use them. In order to measure these dimensions, Likert-scale questions were developed where "1" reflects "Strongly disagree" and " 5 " reflects "Strongly agree". There were 24 items identified in this section and most of them were adopted from the previous studies carried out in similar countries, as well as from the current literature in the cloud computing area with necessary amendments to be compatible with the study's context. The second section of the questionnaire covered demographic information including respondents' gender, their age, education, and the level of usage of cloud computing systems. The questionnaire was prepared and distributed in the English language.

The collected data was then analyzed using PLS including all the required and corresponding validity measures. The selection of this technique was inspired by Hair, et al. [24] and from other related studies performed in the cloud computing systems adoption. It is noteworthy that the analysis was conducted using the PLS software.

\section{RESULTS AND DISCUSSION}

\subsection{Respondents' profile}

Table 1 demonstrates the respondents' profile which shows that the female respondents were nearly $80 \%$, while male respondents were $20 \%$. In terms of age, $88 \%$ of the respondents are between 20 and 30 years old, $6 \%$ of them are between 31 and 40 years old, $4.4 \%$ are below 20 years old, and $1.6 \%$ of the respondents are aged between 41 and 50 years old. With regards to educational level, nearly $84 \%$ of the respondents are holding undergraduate degrees, and around $8 \%$ of the sample is postgraduate degrees' holders, while $8 \%$ of the respondents are holding high school certificates. It is noteworthy that about $49 \%$ of the respondents are members of cloud computing systems, while $51 \%$ of the respondents are not.

Table 1. Respondents' profile

\begin{tabular}{ccccc}
\hline \multicolumn{2}{c}{ Characteristic } & Frequency & Percentage & Cumulative percentage \\
\hline \multirow{4}{*}{ Age } & Below 20 & 8 & 4.4 & 4.4 \\
& $20-30$ & 161 & 88.0 & 92.3 \\
& $31-40$ & 11 & 6 & 98.4 \\
Gender & $41-50$ & 3 & 1.6 & 100 \\
& Above 50 & - & - & - \\
& Male & 37 & 20.2 & 20.2 \\
Education level & Female & 146 & 79.8 & 100 \\
& High school & 15 & 8.2 & 8.2 \\
Membership of & Undergraduate & 153 & 83.6 & 91.8 \\
cloud computing & Postgraduate & 15 & 8.2 & 100.0 \\
\hline
\end{tabular}




\subsection{Model reliability and validity}

The reliability and validity assessment of the data and the model is performed before the testing hypotheses. Particularly, four criteria are scrutinized and evaluated, namely, the Cronbach Alpha, the items' loading, the internal composite reliability (CR), and the average variance extracted (AVE). The factor loadings and (AVE) should be at least equal to 0.5, while the Cronbach Alpha should be at least 0.6 [25][27]. By looking to Table 2, all values of factor loadings were above 0.5 , in order to enhance the internal reliability any items value loadings below 0.65 were omitted. The value of AVE of all items was above than 0.5. Finally, the values of Cronbach Alpha were greater than 0.6. This was observed for all iteration levels. Hence, the model of this study is meeting all the reliability and validity criteria.

Table 2. Measurement model evaluation - convergent validity

\begin{tabular}{|c|c|c|c|c|c|c|c|c|c|}
\hline \multirow{2}{*}{ Constructs } & \multirow{2}{*}{ Items } & \multicolumn{4}{|c|}{ First iteration } & \multicolumn{4}{|c|}{ Final iteration } \\
\hline & & Loading & AVE & $\mathrm{CR}$ & Alpha & Loading & AVE & $\mathrm{CR}$ & Alpha \\
\hline \multirow{5}{*}{ Intention } & Inte. 1 & 0.768 & \multirow{5}{*}{0.549} & \multirow{5}{*}{0.858} & \multirow{5}{*}{0.793} & 0.770 & \multirow{5}{*}{0.549} & \multirow{5}{*}{0.858} & \multirow{5}{*}{0.793} \\
\hline & Inte. 2 & 0.665 & & & & 0.691 & & & \\
\hline & Inte. 3 & 0.712 & & & & 0.713 & & & \\
\hline & Inte. 4 & 0.787 & & & & 0.785 & & & \\
\hline & Inte. 5 & 0.764 & & & & 0.762 & & & \\
\hline \multirow{5}{*}{ Perceived ease of use } & P.Ease.1 & 0.790 & \multirow{5}{*}{0.569} & \multirow{5}{*}{0.868} & \multirow{5}{*}{0.809} & 0.822 & \multirow{5}{*}{0.624} & \multirow{5}{*}{0.869} & \multirow{5}{*}{0.798} \\
\hline & P.Ease. 2 & 0.812 & & & & 0.835 & & & \\
\hline & P.Ease. 3 & 0.721 & & & & 0.737 & & & \\
\hline & P.Ease. 4 & 0.685 & & & & Omitted & & & \\
\hline & P.Ease. 5 & 0.756 & & & & 0.761 & & & \\
\hline \multirow{5}{*}{ Perceived usefulness } & P.usef.1 & 0.819 & \multirow{6}{*}{0.558} & \multirow{6}{*}{0.863} & \multirow{5}{*}{0.801} & 0.834 & \multirow{5}{*}{0.614} & \multirow{5}{*}{0.864} & \multirow{6}{*}{0.790} \\
\hline & P.usef.2 & 0.771 & & & & 0.792 & & & \\
\hline & P.usef.3 & 0.741 & & & & 0.769 & & & \\
\hline & P.usef.4 & 0.663 & & & & Omitted & & & \\
\hline & P.usef.5 & 0.733 & & & & 0.736 & & & \\
\hline \multirow[b]{2}{*}{ Reliability } & Reliab.1 & 0.705 & & & \multirow{3}{*}{0.676} & 0.705 & \multirow{3}{*}{0.604} & \multirow{3}{*}{0.820} & \\
\hline & Reliab.2 & 0.781 & \multirow[t]{2}{*}{0.604} & \multirow[t]{2}{*}{0.820} & & 0.781 & & & 0.676 \\
\hline & Reliab.3 & 0.840 & & & & 0.840 & & & \\
\hline & Resp.1 & 0.715 & & & & 0.695 & & & \\
\hline & Resp.2 & 0.738 & & & & 0.759 & & & \\
\hline & Resp.3 & 0.715 & & & 0812 & 0.740 & 0557 & 0862 & \\
\hline Kesponsiveness & Resp.4 & 0.748 & 0.510 & 0.805 & 0.812 & 0.763 & 0.531 & 0.862 & 0.801 \\
\hline & Resp.5 & 0.633 & & & & Omitted & & & \\
\hline & Resp.6 & 0.755 & & & & 0.771 & & & \\
\hline
\end{tabular}

As mentioned that three items were excluded based on the cross loadings as shown in Table 3 [28]. Particularly, one item was excluded from the perceived ease of use construct, one item from the perceived usefulness construct, and one from the responsiveness construct. The remaining items were all included in the measurement of their respective constructs.

In contrast, discriminant validity was tested to confirm the constructs included in the model are differed significantly from each other [29]. There are many methods to assess the discriminant validity. The regression matrix method was used in this study to evaluate the collinearity between the explanatory variables by looking to regression coefficients value. The preferably value of regression coefficient should be lower than 0.9. In Table 4, the regression coefficient value indicates that this condition is acceptable satisfied. Hence, the discriminant validity criteria are achieved in the model.

\subsection{Hypothesis testing}

Following the model's validity evaluation, the study inspected the main structural model shown in Figure 1. In current regression model, 5000 bootstraps were applied on 183 questionnaires in order to assess the importance of the models' path coefficients [24]. The path analysis in Table 4 indicates that all the study hypotheses are supported, as shown by the p-value which is lower than 0.05 for all the variables. Nevertheless, perceived ease of use is found to have the strongest effect on cloud computing usage. Specifically, the results revealed that perceived ease of use has a significant positive effect on the intention to use cloud computing (H1), perceived usefulness has a significant positive effect on the intention to use cloud computing (H2), reliability has a significant positive impact on the users' intention to opt for cloud computing services (H3), and responsiveness has a significant positive impact on the users' intention to opt for cloud computing tools (H4). These findings are in line with the TAM model [8], [17], [18], [23]. 
Although the cloud computing systems are proven to be easy to access and use, relatively more useful compared to the traditional tools, reliable and responsive, these aspects have to be scrutinized in the marketing and advertising campaigns of these services' providers as well as the higher education institutions [30]. This would potentially increase the usage and popularity of these systems among higher education students in Oman and similar settings [20].

As such, all model's variables are significantly influencing the usage of cloud computing systems in the Omani higher education sector. These factors explain more than $70 \%$ of the variation in the intention to use cloud computing systems in Oman.

Table 3. Cross loading

\begin{tabular}{cccccc}
\hline & Intention & Perceived ease of use & Perceived usefulness & Reliability & Responsiveness \\
\hline Inte.1 & 0.770 & 0.552 & 0.524 & 0.554 & 0.545 \\
Inte.2 & 0.691 & 0.410 & 0.541 & 0.519 & 0.607 \\
Inte.3 & 0.713 & 0.585 & 0.488 & 0.476 & 0.511 \\
Inte.4 & 0.785 & 0.591 & 0.597 & 0.508 & 0.619 \\
Inte.5 & 0.762 & 0.607 & 0.535 & 0.425 & 0.497 \\
P.Ease1 & 0.610 & 0.822 & 0.576 & 0.475 & 0.617 \\
P.Ease2 & 0.601 & 0.835 & 0.537 & 0.369 & 0.527 \\
P.Ease3 & 0.540 & 0.737 & 0.407 & 0.431 & 0.435 \\
P.Ease5 & 0.594 & 0.761 & 0.553 & 0.436 & 0.521 \\
P.usef.1 & 0.643 & 0.605 & 0.834 & 0.520 & 0.678 \\
P.usef.2 & 0.573 & 0.488 & 0.792 & 0.491 & 0.563 \\
P.usef.3 & 0.549 & 0.498 & 0.769 & 0.479 & 0.576 \\
P.usef.5 & 0.497 & 0.464 & 0.736 & 0.479 & 0.499 \\
Reliab.1 & 0.419 & 0.315 & 0.415 & 0.705 & 0.510 \\
Reliab.2 & 0.484 & 0.429 & 0.486 & 0.781 & 0.493 \\
Reliab.3 & 0.629 & 0.495 & 0.550 & 0.840 & 0.605 \\
Resp.1 & 0.567 & 0.457 & 0.612 & 0.548 & 0.695 \\
Resp.2 & 0.515 & 0.501 & 0.514 & 0.521 & 0.759 \\
Resp.3 & 0.571 & 0.527 & 0.518 & 0.475 & 0.740 \\
Resp.4 & 0.519 & 0.496 & 0.509 & 0.473 & 0.763 \\
Resp.6 & 0.614 & 0.507 & 0.609 & 0.560 & 0.771 \\
\hline
\end{tabular}

Table 4. Path coefficients with $t$-values for the structural model

\begin{tabular}{ccccccc}
\hline Hypothesis & Relationship & St. Beta & St. Error & T-Value & P-Value & Decision \\
\hline H1 & Perceived ease of use $\rightarrow$ Intention & 0.352 & 0.070 & 5.031 & 0.000 & Supported** \\
H2 & Perceived usefulness $\rightarrow$ Intention & 0.197 & 0.080 & 2.454 & 0.014 & Supported* \\
H3 & Reliability $\rightarrow$ Intention & 0.193 & 0.065 & 2.984 & 0.003 & Supported** \\
H4 & Responsiveness $\rightarrow$ Intention & 0.236 & 0.084 & 2.819 & 0.005 & Supported** \\
\hline
\end{tabular}

Significant at $\mathrm{P}^{* *} \leq 0.01, \mathrm{P}^{*} \leq 0.05$

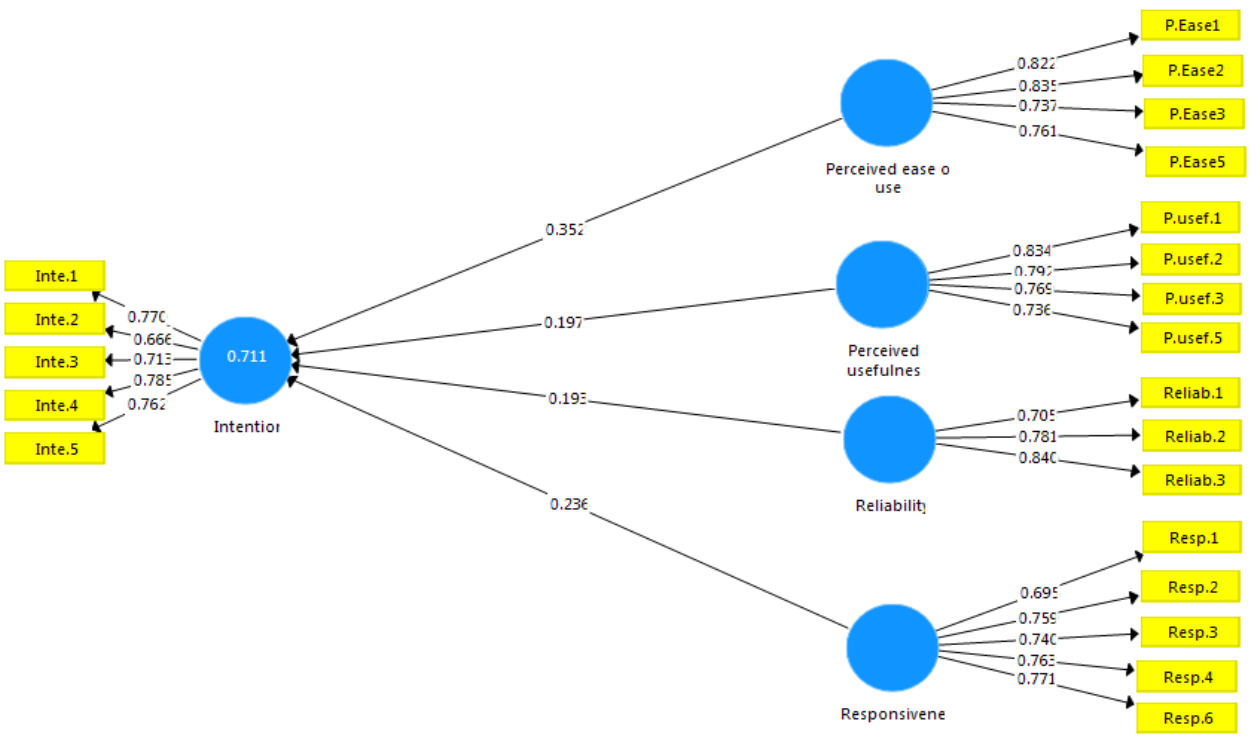

Figure 1. Structural model 


\section{CONCLUSION}

The purpose of the study was to unravel the factors that affect the intention to use cloud computing systems within the higher education sector in Oman. The findings revealed that the use of cloud computing in this context is highly depending on its perceived ease of use, usefulness, perceived reliability and responsiveness. These findings are of great importance as they provide insights to higher education institutions as well as the cloud computing service providers on the main characteristics and aspects that should be emphasized to increase and enhance the usage of these systems among higher education students. Particularly, cloud computing should be made easy to use and access to students. This can be achieved by simplifying their platforms and access methods in a way that suits new users. Nevertheless, this should not be done at the expense of the reliability of these services and their timely responses to the students' needs and requirements. In addition, the usefulness of cloud computing compared to the traditional methods has to be emphasized to the students. This is particularly important of period of crises like COVID-19 outbreak, where cloud computing has shown a great ability to smoothen the teaching and learning activities, and to serve as an efficient tool for knowledge sharing across the globe.

However, the implementation and usage of cloud computing in the higher education sector, and other supporting sectors, requires a significant investment in information and communication technology infrastructure. This also requires support from the energy sector as well as the telecommunication services sector to provide an efficient learning experience to students. On the other hand, the model used in this study provides a remarkable and significant contribution to the behavioral theories by extending the existing behavioral models, mainly the technology acceptance model. Furthermore, the current study findings offer empirical evidence and support to the current model validity and its suitability for similar countries.

Future recommendation for academic work applies the same model in different contexts and rather via more updated and comprehensive models. Moreover, the future researches are advised to extend the sample in the same context and widen the scope of the study to compare between students at different types of higher educations, and different study majors.

\section{REFERENCES}

[1] S. Tadesse and W. Muluye, "The impact of COVID-19 pandemic on education system in developing countries: A review," Open Journal of Social Sciences, vol. 8, no. 1, pp. 159-170, 2020.

[2] UNICEF. The impact of school closures on children's nutrition. UNICEF, New York, 2021.

[3] Q.A. Alajmi, A. Kamaludin, R.A. Arshah, and M.A. Al-Sharafi, "The Effectiveness of Cloud-Based E-Learning towards Quality of Academic Services: An Omanis' Expert View," International Journal of Advanced Computer Science and Applications, vol. 9, no. 4, pp. 158-164, 2018.

[4] I.N.S. Al-Ghatrifi, "Cloud computing: A key enabler for higher education in Sultanate of Oman," International Conference on Computer, Communications, and Control Technology, Sarawak, Malaysia, 2015, pp. 70-72.

[5] Z. Shana and E. Abulibdeh, "Cloud computing issues for higher education: theory of acceptance model," International Journal of Emerging Technologies in Learning, vol. 12, no. 11, pp. 168-184, 2017.

[6] M.T. Amron, R. Ibrahim, and S. Chuprat, "A review on cloud computing acceptance factors," Procedia Computer Science, vol. 124, no. 1, pp. 639-646, 2017.

[7] A. Shahzad, A.G. Golamdin, and N.A. Ismail, "Opportunity and challenges using the cloud computing in the case of Malaysian higher education institutions," The International Journal of Management Science and Information Technology, vol. 20, no. 1, pp. 1-18, 2016.

[8] S. Chen, J. Chen, and S.C. Chang, "Understanding the Antecedents of Individuals Intention of Using Cloud Services," Journal of Economics and Management, vol. 13, no. 2, pp. 139-166, 2017.

[9] M.A. Al-Sharafi, R.A. Arshah, and E.A. Abu-Shanab, "Factors Influencing the Continuous Use of Cloud Computing Services in Organization Level," International Conference on Advances in Image Processing, Bangkok, Thailand, 2017.

[10] A.M.N.A. Kandil, M.A. Ragheb, A.A. Ragab, and M. Farouk, "Examining the effect of TOE model on cloud computing adoption in Egypt," The Business and Management Review, vol. 9, no. 4, pp.113-123, 2018.

[11] M. Stieninger, D. Nedbal, W. Wetzlinger, G. Wagner, and M.A. Erskine, "Factors influencing the organizational adoption of cloud computing: A survey among cloud workers," International Journal of Information Systems and Project Management, vol. 6, no. 1, pp. 5-23, 2018.

[12] S. Tripathi, "Determinants of Cloud Computing Adoption: A Comparative Study," Pacific Asia Journal of the Association for Information Systems, vol. 11, no. 3, pp. 28-54, 2019.

[13] H., Hassan, M.H.M., Nasir, N. Khairudin, and I. Adon, "Factors influencing cloud computing adoption in small and medium enterprises," Journal of ICT, vol. 16, no. 1, pp. 21-41, 2017.

[14] I. Senarathna, C. Wilkin, M. Warren, W. Yeoh, and S. Salzman, "Factors That Influence Adoption of Cloud Computing: An Empirical Study of Australian SMEs," Australasian Journal of Information Systems, vol. 22, no. 1, pp. 1-31, 2018.

[15] A.S.M. Al-Rawahna, C. Hung, and S. Chen, "Readiness of government organizations for cloud-computing age: An empirical evidence from Jordan,” Journal of Business and Management Sciences, vol. 6, no. 4, pp. 152-162, 2018. 
[16] N.R.A. Salam and S. Ali, "Determining factors of cloud computing adoption: A study of Indonesian local government employees," Journal of Accounting and Investment, vol. 21, no. 2, pp. 312-333, 2020.

[17] F. Sadoughi, O. Ali, and L. Erfannia, "Evaluating the factors that influence cloud technology adoptioncomparative case analysis of health and non-health sectors: A systematic review," Health Informatics Journal, vol. 25, no. 1, pp. 1-129, 2019.

[18] A.B. Nassoura, "Critical success factors for adoption of cloud computing in Jordanian healthcare organizations," International Journal of Scientific \& Technology Research, vol. 9, no. 4, pp. 2798-2803, 2020.

[19] S. Chaveesuk, Wutthirong, and W. Chaiyasoonthorn, "Cloud Computing Classroom Acceptance Model in Thailand Higher Education's Institutes: A Conceptual Framework," International Conference on Information Management and Engineering, Salford, United Kingdom, 2018.

[20] Z. Asadi, M. Abdekhoda, and H. Nadrian, "Understanding and predicting teachers' intention to use cloud computing in smart education," Interactive Technology and Smart Education, vol. 17, no. 1, pp. 14-27, 2019.

[21] N. Ahmed, N. Hoda, and F. Alahmari, "Developing a cloud-based mobile learning adoption model to promote sustainable education," Sustainability, vol. 12, no. 1, pp. 1-18, 2020.

[22] A. Ramluckan and B.V. Niekerk, "Security requirements for cloud computing in crisis management," Journal of Information Warfare, vol. 13, no. 1, pp. 33-46, 2014.

[23] F.D. Davis, "Perceived usefulness, perceived ease of use, and user acceptance of information technology," MIS Quarterly, vol. 13, no. 3, pp. 319-340, 1989.

[24] J.F. Hair, W.C. Black, B.J. Babin, and R.E. Anderson, Multivariate data analysis. Harlow: Pearson Education Limited, 2016.

[25] J.C. Nunnally, Psychometric theory, 2nd edition. New York: McGraw-Hill, 1978.

[26] J.F. Hair, G.T.M. Hult, C.M. Ringle, and M. Sarstedt, A primer on partial least squares structural equation modeling (PLS-SEM). Thousand Oaks, CA: Sage, 2017.

[27] S. Brune, K.T. Stevenson, W. Knollenberg, and C. Barbieri, "Development and Validation of a Children's Agricultural Literacy Instrument for Local Food," Journal of Agricultural Education, vol. 61, no. 3, pp. 233-260, 2020.

[28] R. Maskey, J. Fei, and H. Nguyen, "Use of exploratory factor analysis in maritime research," The Asian Journal of Shipping and Logistics, vol. 34, no. 2, pp. 91-111, 2018.

[29] R.T. Veiga, C. Avelar, L.R.C. Moura, and A.K. Higuchi, "Validation of scales to research the personal financial management," Review of Business Management, vol. 21, no. 2, pp. 332-348, 2019.

[30] B. Ahn and H. Ahn, "Factors Affecting Intention to Adopt Cloud-Based ERP from a Comprehensive Approach," Sustainability, vol. 12, no. 1, pp. 1-26, 2020. 